\title{
TAP Block in Children: Does Inflammation Affect on Pain Score?
}

\author{
Odgerel B. ${ }^{1}$, Sergelen O. $^{2}$, Ganbold L. ${ }^{3}$ \\ ${ }^{1}$ Department of Anesthesiology and Operation block, Children's Hospital, \\ National Center for Mother and Child Health, Ulaanbaatar, Mongolia \\ ${ }^{2}$ Department of Surgery, Mongolian National University of Medical Science, Ulaanbaatar, Mongolia \\ ${ }^{3}$ Department of Anesthesiology and Emergency Medicine, Mongolian National University of Medical Science, \\ Ulaanbaatar, Mongolia
}

Email id - odukal @ yahoo.com, sergelen1956@yahoo.com, ganboldl @ gmail.com

\begin{abstract}
Objective: The aim of this study was to evaluate of analgesic effect of ultrasound guided transversus abdomines plane (TAP) block in children undergoing open laparotomy surgery and compare to children were used general anesthesia (GA) alone. Methods: 60 children aged 3-18 years with ASA I-III classification were randomly enrolled in this study. We divided these children in to two groups: control group (GA alone, $\mathrm{n}=31$ ) and study group (GA+TAP block, $n=29$ ) and also divided each group in two subgroups which were with inflammation and without inflammation. All children were received GA with same techniques. Study group (TAP block group) were assigned to receive ultrasound guided block in both side of abdomen using $0.3 \mathrm{ml} / \mathrm{kg}$ of Bupivacaine $0.25 \%$, but not more than $12 \mathrm{ml}$ in each side. Hemodynamic variables such as heart rate, blood pressure were measured at baseline $\left(\mathrm{T}_{0}\right)$, after induction $\left(\mathrm{T}_{1}\right)$, after skin incision $\left(\mathrm{T}_{2}\right)$, and end of surgery $\left(\mathrm{T}_{3}\right)$, and in the recovery room or ICU, at the $2^{\text {nd }}, 4^{\text {th }}, 6^{\text {th }}$ hours postoperatively and examined pain intensity and analgesic requirement and frequency, also correllation between inflamatory process and pain intensity were studied. Statistic analysis was made in Excel using ANOVA, descriptive analysis, correlation and regression analysis. A p-value $<0.05$ was considered significant. Results: There was no differencies between the two studied groups regarding demographic and clinical characteristics. Intraoperative heart rate elevation was higher in GA group with an inflammation (13.3\%) and the systolic blood pressure changes was higher (4.2\%) after skin incision than study group and GA group without inflammation. Level of WBC had very weak positive and statistically significant correlation with intraoperative opioid usage (GA+Inf: $r=0.029$, $\mathrm{p}=0.023$; TAP+Inf: $\mathrm{r}=0.18, \mathrm{p}=0.016$; GA-Inf: $\mathrm{r}=0.018, \mathrm{p}=0.014$ ) but there was not observed correlation in TAP-Inf group. Postopeative pain score was higher in control group and an analgesic requirement and frequency was much more. Conclusion: Transversus abdomines plane block under ultrasound guidance was easy, safe, reliable and effective analgesic in children undergoing open laparotomy surgery and TAP block is a good component of postoperative multimodal analgesia. The inflammatory process increases pain intensity and intra and postoperative analgesic requirements.
\end{abstract}

Keywords: postoperative pain, regional anesthesia, TAP block, ultrasound guided TAP block

\section{Introduction}

Pain assessment, recognition, physiological and psychological response to pain reception and emotional reaction to pain are different in children regarding to age. Pain management in children depends on multi factors such as neurobiological development to the pain response, the knowledge of pharmocokinetical differences of the pain medicine, an improvement of the methods of pain assessment tools in each age group, and usage of evidence based, safe methods in the clinical practice. ${ }^{[1]-[3]}$

During the surgery arise systemic metabolic and neuro-hormonal complex stress response from local surgical trauma by afferent neural tract and involving the central nervous system.

High dose of opioid may depress hemodynamic and can depress immune function in a dose-dependent fashion, suppress ventilation and cough reflex, and prolong ileus and nausea, which all can delay recovery. All abdominal surgical procedures are followed by pain, which also amplify endocrine metabolic response, autonomic reflexes, nausea and ileus and muscle spasm, and thereby delay restoration of function. Therefore, optimal multimodal treatment of postoperative pain is mandatory in order to enhance recovery and reduce morbidity. The keys of good outcome for the vast majority of patients are 'good analgesia and early mobilization. ${ }^{[4,5]}$ General anesthesia with regional blocks has been shown to inhibit the stress responses to surgery and can influence outcome its beneficial effects on organ function. ${ }^{[6]}$

Major abdominal surgery such as laparotomy and various forms of abdominal wall repair is often associated with severe postoperative pain. ${ }^{[7]}$ The mean component of postoperative pain arises from surgical incisional wound of the abdominal wall. Abdominal wall block is one method of multimodal analgesia to decrease postoperative pain and abdominal muscle spasm. 


\section{International Journal of Innovative Research in Medical Science (IJIRMS) Volume 03 Issue 09 Sept. 2018, ISSN: 2455-8737, Imp. Factor - 4.102 \\ Available online at $-\underline{w w w . i j i r m s . i n}$}

Successful regional anesthesia relies on the accurate location of the target nerve, accurate placement of the needle in close proximity to the nerve and accurate volume and the placement of local anesthetic solution around the nerve. ${ }^{[8]}$

The present study was undertaken to evaluate the effectiveness of transversus abdominis plane (TAP) block for open laparotomy surgery in children with or without peritonitis.

\section{Materials and methods}

1) Ethical statement: Ethical approval for this study was acquired from the Research Ethics Committee (Ethical Committee No 6/3/2015 06) of Mongolian National University of Medical Science on 21 January 2015. Parents of all children were informed verbally the purpose and content of the study before the surgery and signed written informed consent form.

2) Study design: Children between 3-18 years of ages, ASA (American Society of Anesthesiologists) I-III class, admitted to the General Surgical departments for elective and emergency surgeries such as peritonitis, liver and intestinal surgeries were included in this prospective, controlled randomized study at the National Center for Mother and Child Health of Mongolia from February 2015 to January 2017.

3) Data collection: A total 72 children were enrolled in this study. Children with allergy to local anesthetics, ASA classification IV and more, skin infection at the injection site, and those who refused to participate in the study were excluded from the study. 36 patients were collected from each elective (without inflammation) and emergency (with inflammation) cases and randomized them by sealed envelopes which were numbered sequentially, into two groups: control or general anesthesia group (GA) and study group or general anesthesia with TAP block group (TAP).

Before induction all children were done white blood cell count (WBC). No premedication were done. After establishing venous access, $5 \mathrm{mg} / \mathrm{kg}$ of Theopental sodium (№ 4602565020385, Kurgan, Russia), $2 \mathrm{mcg} / \mathrm{kg}$ of fentanyl (№ 280715, 09052 Moscow, Russia) and $0.5 \mathrm{mg} / \mathrm{kg}$ of Atracrium (Tracrium, Atracrium besylate W277, Glaxo Smithkline Manufacturing S.p.A Parma, Italy) were given to all children. All children were ventilated mechanically via endotracheal tube using volume controlled ventilation mode, calculating tidal volume was $6 \mathrm{ml} / \mathrm{kg}$. Anesthesia was maintained with 1-1.5 MAC isoflurane in air/O2 (FiO2-0.4).

In the TAP group skin was disinfected both side of the abdomen after induction. A $22 \mathrm{G}$ Quenke spinal needle was used to all children who received TAP block under direct visualization of the needle tip by using ultrasound machine (Philips Sparq ultrasound machine) with high frequency linear array transducer 4-12 MZ. The transducer was placed transversely at the midaxillary line between the lower rib and the iliac crest. After identifying the needle tip, external, internal oblique and transversus muscle aponeurosis, the children were injected anterior to posteriorly 0.3 $\mathrm{ml} / \mathrm{kg}$ of bupivacaine $0.25 \%$ (bupivacaine injection C.P., Anawin 0.5\%, Batch№ 51239, Neon Laboratories Limited 28, Mahal Ind. Est., Laves Rd, Andheri (East), Mumbai-400093, India) between internal oblique and transversus muscle aponeurosis (Figure 1.a and Figure 1.b.).

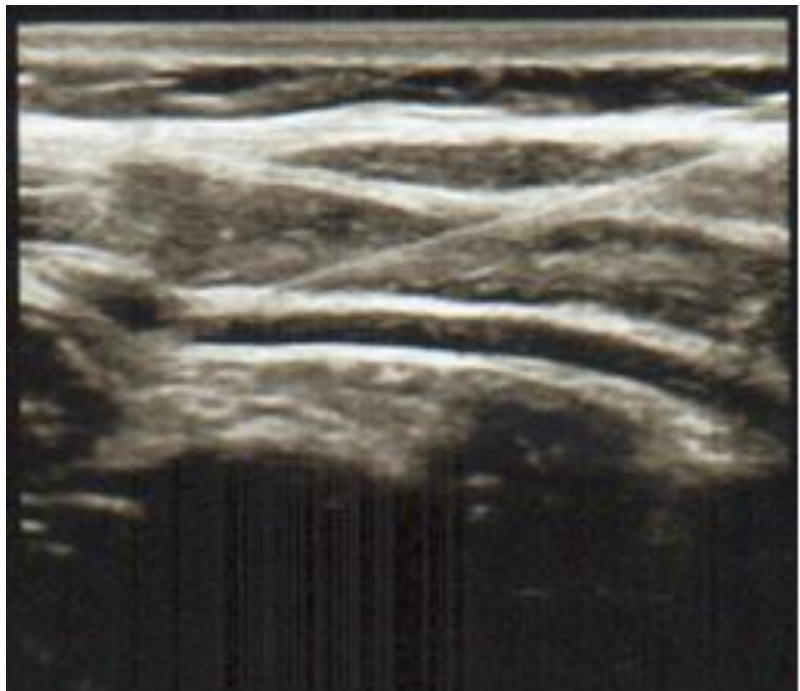

Figure 1.a: Performing TAB block and needle insertion between internal oblique and transversus muscle aponeurosis.

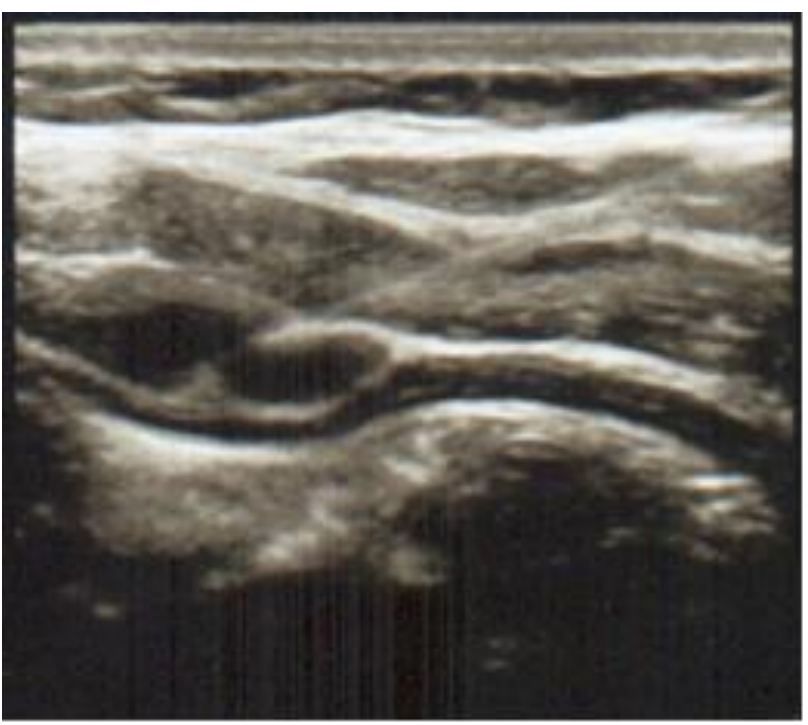

Figure 1.b. Local anesthetic injection at between internal oblique and transversus muscle aponeurosis.

Before the skin incision all children were received $20 \mathrm{mg} / \mathrm{kg}$ BW of Acetaminophen or $2-3 \mathrm{mg} / \mathrm{kg}$ BW of Diclofenac sodium suppositories per rectum.

Intraoperative monitoring included ECG, heart rate, pulse oximetry and NIBP before (baseline) and after induction, immediately after surgical skin incision and at the end of the operation. If the blood pressure and heart rate increased more than $20 \%$ or/and every 30 minutes has been administered of Fentanyl $1-0.5 \mathrm{mcg} / \mathrm{kg}$ of BW according to the duration of the surgery in the control group.

The efficacy of postoperative analgesia was measured using WongBaker facial pain score (Figure 2). ${ }^{[9]}$ 


\section{International Journal of Innovative Research in Medical Science (IJIRMS) Volume 03 Issue 09 Sept. 2018, ISSN: 2455-8737, Imp. Factor - 4.102 \\ Available online at - $\underline{w w w . i j i r m s . i n}$}

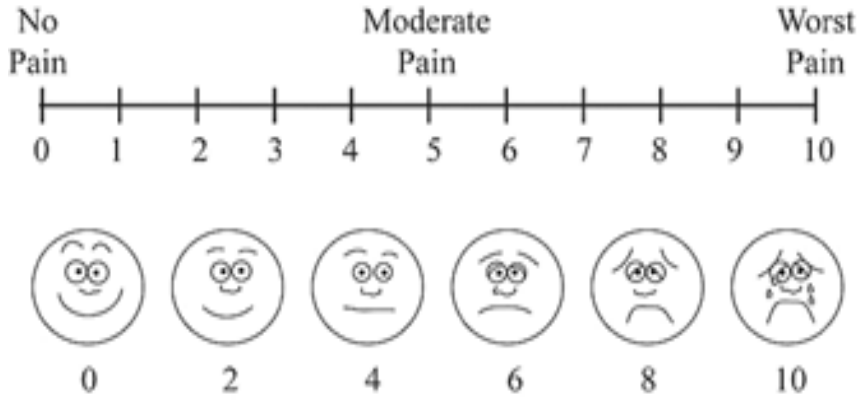

Figure 2: Wong-Baker facial pain score

When the pain score was four or more the children had received acetaminophen $20 \mathrm{mg} / \mathrm{kg}$ rectally or other pain relief medicines.

Pain assessment was made in a recovery room or ICU and at 2nd, 4th, 6th postoperative hours. Postoperative pain evaluation was performed by ICU, recovery room and surgical ward nurses, anesthesiologists and residents who was not involved in the study and who were blinded to the study groups. To prevent false positive or negative result all children were covered both side of the abdomen with tape.

The aim of our study is to assess effectiveness of the TAP block for pain relief in children undergoing open laparotomy with or without peritonitis.

\section{Outcomes}

The primary outcomes are intraoperative hemodynamic changes, opioid usage, postoperative pain score and the time of the first rescue pain medication in each group. The secondary outcome is correlation between WBC count and pain intensity of both study and control group.

\section{Statistical analysis}

The study was powered to find the predicted difference between groups failure rate was $20 \%$ as in our previous study. ${ }^{[10]}$ A type one error protection of 0.05 and a power of 0.80 , and 36 patients in each group were required for appropriate study power. Patient's characteristic, and hemodynamic variables between the groups were compared using an independent Student's t-test. Mean changes of BP and HR were analyzed by using two-way analysis of variance with repeated measurements, followed by ANOVA for multiple comparisons. Correlation was calculated using the Pearson correlation coefficient. The tables show as a mean $\pm \mathrm{SD}$ and number (percentage) of subjects. A p-value $<0.05$ was considered statistically significant.

\section{Results}

Seventy two patients were enrolled in the study but completed sixty patients. Twelve children dropped out the study because of parent's refusal, allergy to LA, changed surgical and anesthesia plan. 31 patients in control group, 29 patients in study group completed the study.

Sixty children with mean age $11.2 \pm 4$ (range $3-18, \mathrm{p}=0.2$ ) years and body weight of $35.4 \pm 13.6$ (range 13-70) $\mathrm{kg}$, were included in the study. The patient characteristics were similar in all groups with regard to age, weight, height, BMI and the usage of fentanyl and muscle relaxant intraoperatively. However, the surgical $(\mathrm{p}=0.0003)$, anesthesia time $(\mathrm{p}=0.002)$ and WBC count $(\mathrm{p}=0.0002)$ were different statistically significant (Table 1 ).

WBC count was higher in children with peritonitis which need emergency laparotomy (with Inflammation: 15.72 $\pm 6.9[\mathrm{Cl} 95 \%$, 5.1-32.5]) than who need elective surgery (without inflammation: 9.025 $\pm 3.9[\mathrm{Cl} 95 \%, 3.5-19])$.

Intraoperative opioid usage was statistically significant and very weak relationship with $\mathrm{WBC}$ in the inflammatory $(\mathrm{GA}+\mathrm{Inf}$ and TAP+Inf) and GA-Inf groups, whereas TAP-Inf group there was relationship (TAP-Inf: $\quad \mathrm{r}=0.27, \quad \mathrm{p}=0.38) \quad$ but statistically insignificant (Table 2).

Table1: Demographic and intraoperative data

\begin{tabular}{|c|c|c|c|c|c|c|}
\hline \multicolumn{2}{|c|}{ Demographic data* (Student $t$ test*) } & \multicolumn{2}{|c|}{ Control group $(n=31)$} & \multicolumn{3}{|c|}{ Study group (n=29) } \\
\hline & $\mathrm{n}=60$ & $\begin{array}{l}\text { GA+Inf } \\
(n=15)\end{array}$ & $\begin{array}{l}\text { GA-Inf } \\
(n=16)\end{array}$ & $\begin{array}{c}\text { TAP+Inf } \\
(\mathrm{n}=15)\end{array}$ & $\begin{array}{l}\text { TAP-Inf } \\
(\mathrm{n}=14)\end{array}$ & p- value \\
\hline Age (year) & $11.2 \pm 4$ & $10 \pm 4.2$ & $10.1 \pm 4.4$ & $13 \pm 3.2$ & $11.5 \pm 3.4$ & 0.2 \\
\hline Gender (male/female) & $35 / 25$ & $10 / 5$ & $8 / 7$ & $7 / 9$ & $10 / 4$ & \\
\hline Body weight (kg) & $35.4 \pm 13.6$ & $35.9 \pm 16.7$ & $31.2 \pm 14$ & $39.3 \pm 11.9$ & $35.6 \pm 10.8$ & 0.42 \\
\hline Height $(\mathrm{cm})$ & $137.3 \pm 18.4$ & $135.8 \pm 20.3$ & $132.9 \pm 21.1$ & $144.2 \pm 14.7$ & $136.4 \pm 16.8$ & 0.37 \\
\hline Body mass index $\left(\mathrm{kg} / \mathrm{m}^{2}\right)$ & $18.3 \pm 3.3$ & $18.8 \pm 4.4$ & $17.3 \pm 2.9$ & $18.4 \pm 3.1$ & $18.7 \pm 2.8$ & 0.56 \\
\hline \multicolumn{7}{|l|}{ Intraoperative data ${ }^{* * *}$} \\
\hline Surgical time (min) & $90.1 \pm 55.4$ & $86.7 \pm 36.4$ & $131.6 \pm 71.3$ & $51.3 \pm 19.3$ & $87.9 \pm 48.8$ & $0.0003 * *$ \\
\hline Anesthesia time (min) & $121 \pm 65.4$ & $122.7 \pm 47.8$ & $165.3 \pm 81.5$ & $80.7 \pm 35.2$ & $111.8 \pm 59.7$ & $0.002 * *$ \\
\hline White blood cells $\left(\times 10^{9} / 1\right)$ & $12.4 \pm 6.5$ & $16.3 \pm 7.3$ & $10.1 \pm 4$ & $15.1 \pm 6.7$ & $7.8 \pm 3.6$ & $0.0002 * *$ \\
\hline Fentanyl dose (mcg/kg/h) & $2.7 \pm 0.8$ & $2.9 \pm 0.9$ & $2.7 \pm 0.8$ & $2.8 \pm 0.7$ & $2.5 \pm 0.6$ & 0.8 \\
\hline Atracrium dose (mg/kg/h) & $0.38 \pm 0.17$ & $0.37 \pm 0.24$ & $0.36 \pm 0.16$ & $0.37 \pm 0.11$ & $0.4 \pm 0.17$ & 0.87 \\
\hline
\end{tabular}

*Data are presented as mean and standard deviation. ${ }^{* *}$ statistically significant, ${ }^{* * * A N O V A}$ multiple comparisons 
International Journal of Innovative Research in Medical Science (IJIRMS)

Volume 03 Issue 09 Sept. 2018, ISSN: 2455-8737, Imp. Factor - 4.102

Available online at $-\underline{w w w . i j i r m s . i n}$

Table 2: The relation of WBC to intraoperative opioid and postoperative requirements of pain relief medicine

\begin{tabular}{|c|c|c|c|c|c|c|c|}
\hline \multirow{2}{*}{\multicolumn{2}{|c|}{ Data*** }} & \multirow[b]{2}{*}{$\mathrm{n}=60$} & \multicolumn{2}{|c|}{ Control group $(n=31)$} & \multicolumn{3}{|c|}{ Study group $(\mathrm{n}=29)$} \\
\hline & & & $\begin{array}{l}\text { GA+Inf } \\
(\mathrm{n}=15)\end{array}$ & $\begin{array}{l}\text { GA-Inf } \\
(\mathrm{n}=16)\end{array}$ & $\begin{array}{l}\text { TAP+Inf } \\
(\mathrm{n}=15)\end{array}$ & $\begin{array}{l}\text { TAP-Inf } \\
(\mathrm{n}=14)\end{array}$ & p- value \\
\hline \multicolumn{8}{|l|}{ Intraoperative } \\
\hline \multicolumn{2}{|l|}{$\begin{array}{l}\text { The relationship WBC and fentanyl } \\
\text { usage* }\end{array}$} & \multicolumn{2}{|c|}{$\begin{array}{l}\mathrm{p}=0.023 \\
\mathrm{r}=0.029\end{array}$} & $\begin{array}{l}\mathrm{p}=0.014 \\
\mathrm{r}=0.018\end{array}$ & $\begin{array}{c}\mathrm{p}=0.016 \\
\mathrm{r}=0.18\end{array}$ & $\begin{array}{l}\mathrm{p}=0.38 \\
\mathrm{r}=0.27\end{array}$ & \\
\hline \multicolumn{8}{|l|}{ Postoperative data } \\
\hline \multicolumn{2}{|c|}{ The patients who received pain relief in the RR and ICU } & $\begin{array}{l}60 / 36 \\
(60 \%)\end{array}$ & $\begin{array}{l}15 / 12 \\
(80 \%)\end{array}$ & $\begin{array}{c}16 / 9 \\
(56 \%)\end{array}$ & $\begin{array}{c}15 / 8 \\
(53 \%)\end{array}$ & $\begin{array}{c}14 / 7 \\
(50 \%)\end{array}$ & \\
\hline \multicolumn{2}{|c|}{$\begin{array}{l}\text { The patients who received pain relief at the } 2^{\text {nd }} \text { hours } \\
\text { postoperatively }\end{array}$} & $\begin{array}{l}60 / 35 \\
(58 \%)\end{array}$ & $\begin{array}{l}15 / 11 \\
(73 \%)\end{array}$ & $\begin{array}{l}16 / 14 \\
(88 \%)\end{array}$ & $\begin{array}{c}15 / 6 \\
(40 \%)\end{array}$ & $\begin{array}{c}14 / 4 \\
(29 \%)\end{array}$ & \\
\hline \multirow{4}{*}{$\begin{array}{l}\text { The patient's number of using pain } \\
\text { medicine within } 2 \text { hours }\end{array}$} & 1 medicine & 15 & 2 & 3 & 3 & 7 & \\
\hline & 2 medicines & 23 & 5 & 10 & 4 & 4 & \\
\hline & 3 medicines & 9 & 6 & 1 & 2 & - & \\
\hline & 4 medicines & 2 & 1 & 1 & - & - & \\
\hline \multicolumn{2}{|c|}{$\begin{array}{l}\text { The patient's number of using pain medicine at the } 4^{\text {th }} \\
\text { hours }\end{array}$} & $\begin{array}{l}60 / 12 \\
(20 \%)\end{array}$ & $\begin{array}{c}15 / 2 \\
(13 \%)\end{array}$ & $\begin{array}{l}16 / 4 \\
(25 \%)\end{array}$ & $\begin{array}{l}15 / 1 \\
(7 \%)\end{array}$ & $\begin{array}{l}14 / 5 \\
(36 \%)\end{array}$ & \\
\hline \multicolumn{2}{|c|}{$\begin{array}{l}\text { The patient's number of using pain medicine at the } 6^{\text {th }} \\
\text { hours }\end{array}$} & $\begin{array}{l}60 / 37 \\
(62 \%)\end{array}$ & $\begin{array}{c}15 / 6 \\
(40 \%)\end{array}$ & $\begin{array}{l}16 / 12 \\
(75 \%)\end{array}$ & $\begin{array}{c}15 / 9 \\
(60 \%)\end{array}$ & $\begin{array}{l}14 / 10 \\
(71 \%)\end{array}$ & \\
\hline \multicolumn{2}{|l|}{ Pain score in RR or ICU } & $3.7 \pm 1.7$ & $4.9 \pm 2.2$ & $3.6 \pm 1.7$ & $3.5 \pm 0.6$ & $2.7 \pm 1.3$ & $0.0034 * *$ \\
\hline \multicolumn{2}{|l|}{ Pain score after 2 hours } & $3.6 \pm 2.5$ & $4.6 \pm 2.8$ & $4.4 \pm 1.99$ & $3.1 \pm 2.7$ & $2.3 \pm 2.05$ & $0.04 * *$ \\
\hline \multicolumn{2}{|l|}{ Pain score after 4 hours } & $3.35 \pm 1.55$ & $3.25 \pm 1.3$ & $3.96 \pm 1.5$ & $2.77 \pm 1.5$ & $3.38 \pm 1.8$ & 0.199 \\
\hline \multicolumn{2}{|l|}{ Pain score after 6 hours } & $3.65 \pm 1.35$ & $3.74 \pm 1.41$ & $4.19 \pm 1.49$ & $3.23 \pm 1.12$ & $3.37 \pm 1.23$ & 0.193 \\
\hline
\end{tabular}

*Regression, $* *$ Statistically significant, $* * * A N O V A$

After recovery and at the first two postoperative hours the pain score was statistically significant higher in control group ( $\mathrm{p}=0.0034$ and $\mathrm{p}=0.04$, respectively) and early usage of pain relief medications. The highest pain score was in GA+Inf group, while the lowest one was in TAP-Inf group $(4.9 \pm 2.2$ and $2.7 \pm 1.3$, respectively).

Heart rate and blood pressure were measured before and after induction, after skin incision and end of surgery (T0, T1, T2, T3, respectively) there was no statistically significant difference $(\mathrm{p}=0.9)$. However, heart rate increased by $13.3 \%$, systolic blood pressure increased by $4.2 \%$ after skin incision and in the end of surgery heart rate elevated by $7 \%$ compared to before induction (T0 ) in GA+Inf group. Regarding to the other groups after induction hemodynamic changes were little and not more than by $3 \%$ (Figure 3).

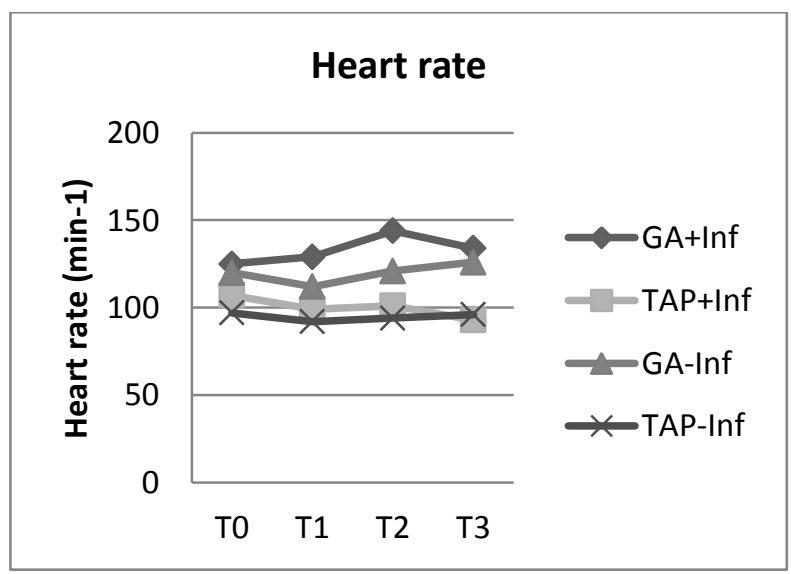

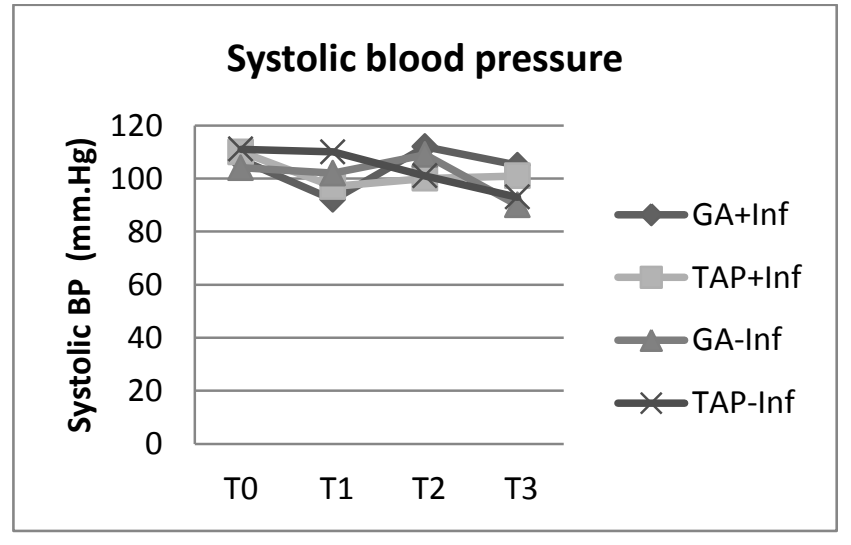

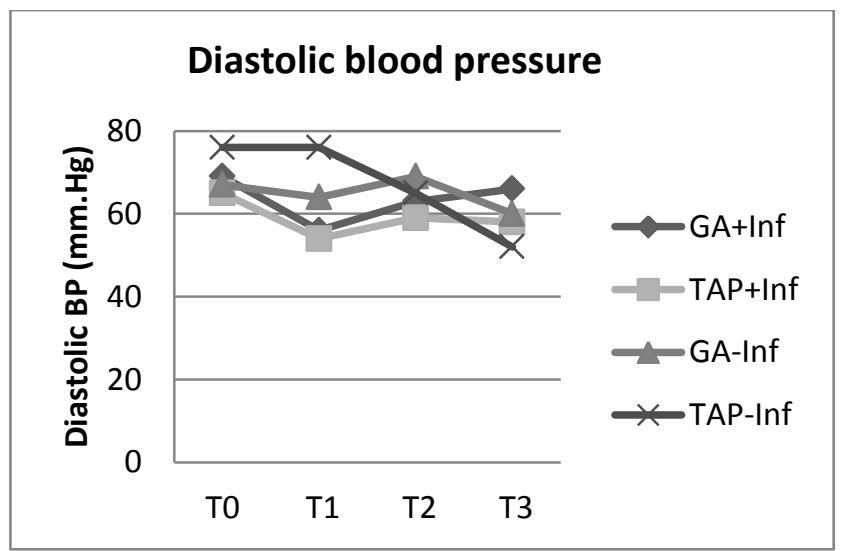

Figure3: Hemodynamic variables at the intraoperative period in all groups*

T0-before induction, T1-after induction, T2-after skin incision, T3end of surgery

*Two way ANOVA with repeated measurements $p=0.9$. 


\section{International Journal of Innovative Research in Medical Science (IJIRMS) Volume 03 Issue 09 Sept. 2018, ISSN: 2455-8737, Imp. Factor - 4.102 \\ Available online at $-\underline{w w w . i j i r m s . i n}$}

In sixty percent of all patients had pain relief in the RR and ICU, from GA+Inf group eighty percent, in other group 50\% of patients received pain relief. $4^{\text {th }}, 6^{\text {th }}$ postoperative hours increased pain intensity in Study group but statistically insignificant.

Postoperative hemodynamic changes were not statistically significant for all groups.

\section{Discussion}

The transversus abdominis plane (TAP) block is a newly developed block involving the nerves of the anterior abdominal wall and it is a relatively simple technique that provides myocutaneus anesthesia that, as a part of a multimodal analgesic treatment, have been used to control somatic surgical pain originating from the skin, muscle, and parietal peritoneum of the abdominal wall. However, TAP block have not been shown to affect surgical outcome unless their provision of optimal pain management is in the context of multimodal analgesia (MMA), and together with changes in organizational surgical care. The result of the better pain relief is earlier mobilization and oral nutrition, both elements necessary to facilitate the return to baseline functions and improve Enhanced Recovery After Surgery (ERAS) program. ${ }^{[11]}$

The TAP block was first described in 2001 by Rafi, in the neurofascial plane between the internal oblique and transversus abdominis muscles through a well-defined by anatomical landmark entrance at the triangle of Petit. ${ }^{[12]}$ Further in 2007, Mc Donnell and others developed and studied the distribution of local anesthetics during this block. ${ }^{[13]}$ In 2006, O'Donnell and others studied the TAP block for prostatectomy surgery and first used the nomenclature "Abdominis transversus plane block". ${ }^{[14]}$ In 2007 Hebbard and et al performed this block by using ultrasound machine and Fredrickson and others first used for 8 children undergoing hernia repair in $2008 .^{[15],[16]}$

Recently, the ultrasound guided TAP block has gained popularity for intraoperative and postoperative pain management in a variety of abdominal surgical procedures in adult, pediatric and neonatal patients. For us, this is a second study of using ultrasound guided TAP block in children.

Using ultrasound guided TAP block for children is increasing undergoing lower abdominal wall operations such as inguinal hernia, ${ }^{[17]-[21]}$ open appendectomy, ${ }^{[22],[23]}$ laparoscopic surgery, ${ }^{[24],[20]}$ laparoscopic repair of undescended testis ${ }^{[25]}$ and urethral reconstructive surgeries. ${ }^{[26]}$ There have many study of TAP block is superior than control and wound infiltration of local anesthetic groups, decreases opioid requirements and longer time need for first analgesic medicine postoperatively, ${ }^{[25],[26],[22]}$ furthermore Dalia and Mafaa concluded TAP block is better than caudal block, ${ }^{[26,18]}$ in study Neha and Ashraf and others results were shown that the result were equal with caudal block. ${ }^{[19],[21]}$

In the present study TAP block decreases the requirement of pain relief medicine and the control group (GA) had higher pain intensity, difficult to treat pain and need more than 3 medicines for postoperative pain relief. In children of all group had some degree of pain, and more than fifty percent of them need pain relief medicine during recovery. All cases were made laparotomy with a wide midline incision. Major abdominal surgery made via a midline incision to ensure adequate and complete exploration of the abdominal cavity not depending on with inflammation or without. $^{[27]}$ We performed the TAP block via midaxillary line anterior to posterior direction and at this level T10-12 nerve branches are anesthetized mostly and it decreases pain sensation of lower and middle part of the abdominal wall. In contrast, upper abdominal wall innervate from T6-9 nerve branches which continue to upper anterior abdominal wall, as named the intercostal nerve plexus ${ }^{[28]}$ For pain relief upper abdominal wall Hebbard and others performed the TAP block via cubcostal approach under ultrasound guidance. ${ }^{[29]}$ We did not use midaxillary and subcostal approaches both avoiding of local anesthetic high dose toxicity. May use these both approaches for some patient that need "J" type incision for liver and open cholecystectomy surgeries.

At the first two hours children from control group received more pain relief, using 2-4 medicines, which were $92 \%$ and $80 \%$ (GA+Inf and GA-Inf, respectively). However, in the study group using more than 2 medicines for pain relief was $67 \%$ and $36 \%$ (TAP+Inf and TAP-Inf, respectively), in which one patient received 3 medicine and there was no patient received 4 medicines (fentanyl, ketamine, acetaminophen, diclofenac or metamizole sodium).

At the $6^{\text {th }}$ postoperative hours increased pain relief medicine usage from $36 \%$ to $71 \%$ in the study group (TAP-Inf) even did not increase pain intensity from $4^{\text {th }}$ hours (pain intensity at the $4^{\text {th }}$ hours: $3.38 \pm 1.83$ vs $6^{\text {th }}$ hours: $3.37 \pm 1.23$ ). It may be because of regarding to our local postoperative pain management protocol that repeats the pain relief medicine after 6 or 8 hours postoperatively.

Acute appendicitis is the most common pediatric abdominal surgical condition and approximately $30 \%$ of the children with appendicitis have perforation ${ }^{[30]}$ which is resulting in intraperitoneal contamination can lead to peritonitis, increase morbidity requiring prolonged treatment. The initial response of the peritoneum against the bacterial contamination is characterized by hyperemia and increases exudates of fluid with phagocytes into the peritoneal cavity. Visceral pain is the arising from internal organs and in comparison to somatic pain, visceral pain is poorly localized, because the density of nociceptors on viscera is lower and afferent fibers are less represented in cortical mapping. Whereas somatic pain is caused by stimuli such as cutting and crushing, visceral structures do not show a painful response to these, but instead respond to distension as well as to inflammation and ischaemia. ${ }^{[31]-[33]}$ The mean symptom in all cases is abdominal pain. The majority of patients lie still, with their knees bent; these maneuvers diminish the tension of the abdominal wall and alleviate the pain. Pain to palpation is the most characteristic sign of peritonitis, to both deep and superficial touch. Initially there is voluntary guarding; subsequently the muscular wall undergoes an involuntary and severe spasm. Diminished abdominal wall compliance due to pain, tight abdominal closure and third-space fluid can increase intraabdominal pressure (IAP).$^{[34],[35]}$ TAP block may reduce muscle tone and decrease IAP.

The white blood cell count may elevate greater than 11.000 cells per ml with left shift in the acute appendicitis and peritonitis. ${ }^{[36],[37]}$ David and others studied to quantify more precisely the accuracy of fever and leukocytosis as indicators of bacteremia. They concluded that a total WBC count provided better information about bacteremia than temperature. WBC count cutoff of $10.000 / \mathrm{mm}^{3}$ increased specificity with minimal decrease in sensitivity ${ }^{[38]}$ In our study a level of WBC had very weak positive 


\section{International Journal of Innovative Research in Medical Science (IJIRMS) Volume 03 Issue 09 Sept. 2018, ISSN: 2455-8737, Imp. Factor - 4.102 \\ Available online at - $\underline{w w w . i j i r m s . i n}$}

and statistically significant correlation with intraoperative opioid usage in group except TAP-Inf. May be it means inflammation aggravated pain intensity and increase the requirement of pain relief medicine. In the groups with inflammation (GA+Inf and TAP+Inf) the postoperative pain in recovery room and ICU was higher in control group $(4.9 \pm 2.2$ vs $3.5 \pm 0.6)$ and the number of the children who received first rescue medication was greater ( $80 \%$ vs 53\%) which were statistically significant. We did not find a similar study, except our previous randomized control trial, which was using TAP block in 78 children undergoing open appendectomy surgery, the level of WBC had direct positive relationship with appendix inflamation (GA group $n=40: r=0.499$ ( $\mathrm{p}$-value=0.001), TAP group $n=38: r=0.55$ ( $\mathrm{p}$-value $=0.0004)$ ) and weak positive correlation $(\mathrm{r}=0.25(\mathrm{p}-\mathrm{yтга}=0.03))$ with pain intensity in control group. In contrast there was no relationship between WBC and pain intensity in the study group $(\mathrm{r}=0.001(\mathrm{p}-\mathrm{-утга}=0.9))^{\cdot[10]}$

\section{Limitation}

We had some limitations of this study. Firstly, to increase statistic power we need to involve more patients in each groups in the future study. Secondly, we only took WBC as an inflammatory indicator that had not been sufficient to fully describe the inflammatory response of the pain intensity. Furthermore, the postoperative protocol for treatment is recommended for 6 hours, which may have caused the some patients to tolerate of the pain. In the future, this study needs to be expanded.

\section{Conclusion}

Ultrasound guided TAP block is easy, safe, reliable and effective analgesic in children undergoing open laparotomy surgery and TAP block is a good component of postoperative multimodal analgesia. The inflammatory process increases pain intensity and may be also increase intra and postoperative analgesic requirements.

\section{Conflict of interest}

There is no complicit of interest.

\section{Corresponding author}

Odgerel Boldbaatar, MD, FBARTC. Pediatric anesthesiologist, Department of pediatric anesthesiology and Operating block, Children's Hospital, National Center for Mother and Child Health, Khuvisgalchdiin Street, Ulaanbaatar 16060, Mongolia

\section{References}

[1] Walker SM., Pain in children: recent advances and ongoing challenges. Br J Anesth 2008; 101(1): 101-110

[2] Aizenberg VL, Ulrikh GE, Tseepin LE, Zabolotskii DL. Regional anesthesia in pediatrics. Continuous central and peripheral nerve blocks in postoperative period. J Reg Anesth Acute Pain. (in Russian) 2014; 8(4): 41-49

[3] Kulshrestha A, Sukhminder JSB. Special articleManagement of acute postoperative pain in pediatric patients. Anesth Pain Int Care 2014; 18(1): 101-105

[4] Wolf AR. Effects of regional analgesia on stress responses to pediatric surgery. Pediatr Anesth 2012; 22: 19-24
[5] Keilet H. Multimodal approach to control postoperative pathophysiology and rehabilitation. Br J Anesth 1997; 78: 606-617.

[6] Sendasgupta C, Makhija N, Kiran U, Choudhary SK, Lakshmy R, Sambhu ND. Caudal epidural sufentanil and bupivacaine decreases stress response in pediatric cardiac surgery. An Card Anesth 2009; 12:(1) 27-33

[7] Børglum J and others, Ultrasound-Guided Bilateral Dual Transversus Abdominis Plane Block: A New Four-Point Approach. Acta Anaesth Scand. 2011; 55(6): 658-63

[8] Galante D, Caruselli M, Dones F. Review articleUltrasound guided transversus abdominis plane (TAP) block in pediatric patients: Not only a regional anesthesia technique for adults. Anesth Pain Intensive Care. 2012;16(2): 201-204

[9] Wong DL, Baker C. Pain in children: comparison of assessment tools. Pediatr Nurs 1998;14:9-17

[10] Odgerel B, Erdenetsetseg Ch, Sergelen O, Ganbold L. Some results of ultrasound guided abdominal wall block for appendectomy surgery in children. In proceeding of the 5th Young Researchers Congress on Medical Science, Ministry of health, Ulaanbaatar, Mongolia, 17 Nov, 2016

[11] Baldini G, Francesco C. The current and future role of regional anesthesia in Enhanced Recovery After Surgery programs for abdominal surgery. Advances in anesthesia. 2015;33: 39-59.

[12] Rafi F. Abdominal field block: a new approach via the lumbar triangle. Anesth. 2001;50: 1024-1026

[13] McDonnell JG, O'Donnell BD, Farrell T. TAP: A cadaveric and radiological evaluation. Reg Anesth Pain Manage. 2007; 32:399-404

[14] O'Donnell BD, McDonnell JG, McShane. Transversus abdominis plane (TAP) block in open retropubic prostatectomy. Reg Anesth Pain Med. 2006; 31:91

[15] Hebbard P, Fujiwata Y, Shibata Y, Rouse C. Ultrasound guided transversus abdominis (TAP) block. Anaesth Intensive Care. 2007; 35:616-7

[16] Fredrickson MJ, Seal P, Houghton J. Early experience with the transversus abdominis plain block in children. Pediatr Anesth 2008;

[17] Fredrickson MJ, Paine C,Hamill J, Improved Analgesia with the Ilioinguinal Block Compared to the Transversus Abdominis Plane Block after Pediatric Inguinal Surgery: A Prospective Randomized Trial. Paediatr Anaesth. 2010; 20(11): 1022-27

[18] Alsadek MM, Mohamed M, Al-Gohari, Mohamed IE. Ultrasound guided transversus abdominis block versus ultrasound guided caudal block for pain relief in children undergoing lower abdominal surgeries. Egyptian Journal of Anesthesiologists. 2015;31: 155-160

[19] Neha K, Sharmila A. Comparison of Transversus Abdominis Plane Block and Caudal Block for Postoperative Analgesia in Children Undergoing Lower Abdominal Surgery Int J Sci Res. 2015; 4(4): 1585-1587

[20] Joseph DT. Preliminary experience at transversus abdominis plain block for postoperative pain relief in infants and children. Saudi J Anesth 2015; 3(1): 2-6

[21] Ashraf A, Ahmed R. Ultrasound guided transversus abdominal plane (TAP) block versus caudal block for postoperative analgesia in children undergoing unilateral 
open inguinal herniotomy: a comparative study. Res Opinion Anesth Intensive Care. 2014;2: 52-59

[22] Carney $\mathbf{J}$ and others, Ipsilateral Transversus Abdominis Plane Block Provides Effective Analgesia after Appendectomy in Children: A Randomized Controlled Trial. Anesth Analg 2010; 111(4): 998-1003

[23] Ramzy SA. Ultrasound guided transversus abdominis plane block versus local wound infiltration in children undergoing appendectomy: A randomized controlled trial' Egypt J Anaesth 2014;30: 377-382

[24] Sandeman DJ and others, Ultrasound-Guided Transversus Abdominis Plane Blocks for Laparoscopic Appendicectomy in Children: A Prospective Randomized Trial', Br J Anaesth 2011; 106(6) 882-86

[25] Alsadek MM, Rizk SN, Selim MA. Ultrasound guided transversus abdominis block in pediatric patients undergoing laparoscopic surgery. Egypt $\mathrm{J}$ Anesth. 2014;30: 273-278

[26] Dalia M, Fawy El, Hanaa A. Ultrasound guided transversus abdominis block versus caudal block for postoperative pain relief in infants and children undergoing surgical pyeloplasty. Ain Shams J Anesth. 2014;7: 177-181

[27] Carlos A. Ordonez, Juan Carlols Puyana. Management of peritonitis in the critically ill patient. Surg Clin North Am. 2006; 86(6): 1323-1349

[28] Rozen WM, Tran TM, Ashton MW, Barrington M J, Ivanusic J J, Yaylo GI. Refining the course of the thoracolumbar nerves: a new understanding of the innervation of the anterior abdominal wall. 2008; 21 : 325-333

[29] Hebbard P, Barrington MJ, Vasey C. Ultrasound guided continuous oblique subcostal transversus abdominis plain blockade. 2010; 35: 436-441

[30] Addiss DG, Saffer N, Fowler BS et al. The epidemiology of appendicitis and appendectomy in the United States. Am J Epidemiol. 1990; 132: 910-925

[31] Steeds CE. The anatomy and physiology of pain. Surgery. 201634:(2) 55-59

[32] Holzheimer RG. Management of secondary peritonitis. Holzheimer RG, Mannick JA, edidors. Surgical treatment: Evidence-Based and Problem-Oriented. Munich: Zuckschwerdt; 2001

[33] Christopher JG, Husted TL, Solomkin JL. Fever and Abdominal Pain. Infectious disease and antimicrobial agents. http://www.antimicrobe.org/e18.asp

[34] Papavramidis TS, Marinis AD, Pliakos I, Kesisoglou I, Papavramidou N. Abdominal compartment syndromeIntra-abdominal hypertension: Defining, diagnosing, and managing. J Emerg trauma Shock. 20114(2): 279-291.

[35] Hunt L, Frost SA, Hillman K, Newton PJ, Davidson PM. Management of intra-abdominal hypertension and abdominal compartment syndrome: a review. J Trauma management and outcomes. 2014; 8:2

[36] Ha SN, Hong CK, Lee Y, Sung AJ et al. Clinical significance of Fever and Luekocytosis in diagnosis of acute appendicitis in children who visit emergency department with abdominal pain. Int J Clin Pediatr. 2012; 1(1): 9-18.

[37] Bonadio W, Rebillot K, Ukwuoma $\mathrm{O}$ et al. Management of pediatric perforated appendicitis. Comparing outcomes using early appendectomy versus solely medical management. The pediatric infectious disease journal. 2017; 36: 937-941

[38] Jaffe DM, Fleisher GA. Temperature and total white blood cell count as indicators of bacteremia. Pediatrics. 1991; 87(5): 670-674. 